\title{
"Bridging" Engineering \& Art: An Outreach Approach For Middle And High School Students
}

Bahram Asiabanpour, Texas State University- San Marcos, USA

Nicole DesChamps-Benke, Texas State University- San Marcos, USA

Thomas Wilson, Texas State University- San Marcos, USA

Matthew Loerwald, Texas State University- San Marcos, USA

Hannah Gourgey, E3 Alliance, USA

\begin{abstract}
In this paper describes a novel outreach approach to high school and middle school students to familiarize them with engineering functions and methods. In this approach students participated in a seven-day summer research camp and learned many engineering skills and tools such as CAD solid modeling, finite element analysis, rapid prototyping, mechanical tests, team working, and communication skills under a project-based bridge design research project. The project choice was intended to integrate principles of artistic design, creative use of public spaces, as well as principles of engineering design. End of the program survey results showed a good understanding about the engineering skills and functions and a high degree of satisfaction among participants.
\end{abstract}

Keywords: High school; outreach; teaching engineering; project-based

\section{INTRODUCTION}<smiles>C1=C2CCCC(=C1)CC2</smiles>

ngineering is vital to future economic growth of the US and the world. The globalization of the business environment demands that engineers be equipped with new sets of skills. Some of important characteristics of US engineers should be the ability to solve problems that account for "complex interrelationships" and "encompass human and environmental factors"[1]. Additionally, engineers are needed more than ever in the US because of different factors including: (1) industrial processes are becoming increasingly complex that requires more operators with high technical skills; (2) need for research and development in materials and instruments demands engineers with advanced skills; (3)different socio-environmental factors such as aging population in need of more medical devices and equipment; (4) environmental issues and additional regulations which needs more specialists to maintain the safe and clean environment; (5) the growing need for energy that demands more research and development for finding alternative energy sources, and (6) the growth of population and aging infrastructure that requires more development in variety of areas such as transportation, utilities, and communication are contributing to the need for more engineers in variety of fields [2].

According to the National Science Board one of the key challenges in engineering education is to overcome inaccurate perceptions of engineering among high school students and their parents as well as their teachers. Surveys show that the general public is not fully aware of engineering's role in "improving health, the quality of life, and the environment." This inaccurate public belief has resulted in the current stereotype that only those students who are good at math and science and like working with objects rather than people come to engineering programs and those who like team working and finding solutions for social problems have been alienated from engineering programs. "As a result, many students, especially women and minorities, cannot see themselves as engineers."[1] Additionally, statistics show that women and minority groups have higher dropout rates in engineering. The main causes of abandoning engineering programs have been the poor performance in "their first math courses," "lack of role models," and "perceptions of a too competitive and uncaring environment". According to this report "retention of engineering students is a system problem that begins before college." [1] Perception and preparation both play 
influential roles in the recruitment challenges and attrition rates in engineering programs.

The Texas Higher Education Coordinating Board (THECB) has a variety of outreach programs aimed at "Closing the Gaps by 2015" across a wide range of STEM fields in higher education [3]. One of these outreach programs is Engineering Summer Program (ESP). This paper reports the collaborative work between Engineering and Art and Design schools at Texas State University- San Marcos to teach engineering skills and functions to middle school and high school students through an art-themed bridge design project in the form of a one week summer research camp. The goal of this research camp was to address the serious misperceptions about engineering as well as the problem of low participation of underrepresented groups and women in engineering. The objectives of this program were to:

- $\quad$ Familiarize high school students and teachers with engineering concepts and tools

- Teach scientific and technological concepts to middle and high school students by use of hands-on engineering skills in an art themed, fun, competitive, and team working environment

- Introduce participants to creativity within engineering projects and combine engineering principles with artistic design

- $\quad$ Raise awareness of local engineering majors through campus-based summer programs

The introduction of artistic concepts into an engineering research project expands the understanding of human factors in engineered works. For example, the work scope for this research camp expanded beyond its traditional focus on engineering function to include aesthetics as well as user and bystander perspectives into the design process. This inclusion of a wider range of perspective, in turn, tends to strengthen appreciation for the role of engineering to society.

The rest of this paper is organized as follows. In section 2, the theoretical foundation and recent works of the engineering and art interrelationship is presented. In section 3, method including topics, content, and activities are illustrated. Evaluation method and resulted are shown in sections 4 and 5 respectively. Section 6 includes the conclusions.

\section{THEORETICAL FOUNDATION AND RECENT WORKS}

The idea that each side of the brain has a different way of thinking was first proposed by Roger Sperry in 1960s. For this work he received a Nobel Prize in Medicine in 1981[4]. Sperry found that the right side of the brain is visual and processes information in an intuitive and simultaneous way. The "right side" examines the whole picture first, and then the details. It processes ideas simultaneously, makes lateral connections from information, and focuses on images and patterns. The left side of the brain is verbal and processes information in an analytical and sequential way. It observes the pieces and then puts them together, and it focuses on details, makes logical deductions from information, and focuses on words, symbols, and numbers [5].

People in different professions characteristically use either the left or the right brain. Creative artists use the right side of the brain more than the left side. When they begin an art work (e.g., sculpture, painting, etc.) they usually visualize the final form in their mind and then work on details such as elements, matching, colors, etc. [5]. On the other hand, people with professions such as "accounting, law, and economics who use the linear, logical functions" use the left side of the brain more than the right side [6].

According to Professor Brent Strong, engineers can be categorized into three groups: 1. Implementers (leftbrain thinkers) who are focused, skillful in a particular field, read strongly in their field, and are hired into jobs where they use these skills; 2. Innovators (right brain thinkers) who do not have a specific, well-defined task (e.g., new product development, leader), are flexible, read widely and avidly, and usually learn innovative skills independently; and 3. Slugs who rarely read [7].

While jobs for left-brainers (like accounting, law, and computer programming) are important and are still available, many of these occupations face increasing automation, cheaper labor markets and therefore are vulnerable in the current American marketplace to overseas outsourcing. [6]. In his recent book $\underline{A}$ Whole New Mind: Why Right Brainers Will Rule the Future, Daniel Pink says that the importance of right-brainers and non-linear, creative, 
wholistic thinkers such as artists and designers is becoming more obvious to society every day [8].

Concerning engineering, Pink believes that the only engineers who are thriving are those who can do the "basic engineering," and also have "good communication skills," "good inventive skills," and can "understand design." They are "multicultural" and/or "multilingual," and "they have a much more robust set of abilities." In his research he found that many successful people in left-brain jobs have had some background in fine arts. He believes such a background has assisted them to become better leaders, better team members, and better decision maker/problem solvers. Many of these findings are not new for people in arts. Many art teachers believe these are the things they have done for decades [6]. Betty Edwards in her books, Drawing on the Right Side of the Brain (1989), and New Drawing on the Right Side of the Brain Workbook: Guided Practice in the Five Basic Skills of Drawing (2002) has proposed different techniques and exercises to assist people who previously believed they were incapable of drawing [9] and [10].

A few other initiatives have bridged the gap between science and art. For instance, in his recent book Artscience: Creativity in the Post Google Generation, David Edwards, a professor of biomedical engineering at Harvard, addressed the importance of making bridges-between academic, industrial, social, and cultural disciplines as a means for creating high-impact ideas. He believes that some original scientific/artistic works have been made possible only after their innovator/creator has crossed the science/art dividing border. He also thinks that lowering institutional barriers will fuel innovation and cross-disciplinary ideas [11].

\section{PROGRAM DESCRIPTION}

This outreach summer camp research project was offered to 20 middle and high school students who participated in a seven-day research camp. Accepted participants included 10 male and 10 female students and a high school science teacher.

Under this research program students initially learned the following engineering, science, and art related topics:

- $\quad$ Elements of Design (i.e., space, form, line, time, movement, color, texture, light)

- $\quad$ Computer Aided Design (CAD) for solid modeling and fundamentals of design

- $\quad$ Principles of design (i.e. repetition, variety, rhythm, balance, emphasis and economy, proportion)

- $\quad$ Finite Element Analysis (FEA)

- $\quad$ Rapid Prototyping (RP) software and equipment

- $\quad$ Physical and mechanical properties of materials, standards, testing tools and methods

- Team working, project management, and communication skills

The participating students were then assigned a pedestrian bridge design project s over the San Marcos River by incorporating artistic aspects into engineering performance measures.

Through a field trip to the San Marcos river, they practically observed the site and finished measuring important physical specifications (i.e., water flow rate, depth, and width) of the river for the bridge design. Once a basic bridge type was selected, the students learned and used Inventor Autodesk software to design the bridge. Students were given time to select and address artistic design considerations that implemented the art principles and elements of design.

Then the bridges designed by this software, were subjected to simulated loads using built-in Finite Element Analysis (FEA) software (Ansys) to determine if it would be strong enough for the projected loads. Once a bridge design passed the simulated strength test, students learned about Artistic Elements. Prepared presentations addressed the artistic design process (e.g., how ideas are generated for artwork) and introduced participants to the organizing principles and artistic elements of design [12]. Student working groups picked a space and created a form (bridge).

During engineering design project work sessions, artistic aspects were discussed and reinforced with the art instructor. Texture, color, light, as well as time and movement were incorporated into the bridge designs, as selected by individual working groups. Then, the bridge design was transferred to the ZEdit software for adding color and texture, and finally a model bridge was built by the Zcorp 450 rapid prototyping machine. This model was then completed by landscaping. Students also received an overview of different mechanical tests. 
The overview included theory, standard, equipment, and test method for tension, compression, shear, impact, and fatigue tests. For the hands-on activity in this section, instead of breaking their model bridge, they tested smaller sample parts. The Figure 1 illustrates some of the activities in this program. Students in each team also prepared a poster that summarized the entire camp activities. A panel of experts including various faculty from engineering and art programs as well as experts from industry sector and a product designer and innovator evaluated the final projects. There presentation followed by question/answer and comments from the panel. During this camp, some other activities included visiting labs and workshops in engineering, technology, and art departments, playing videos on world's famous bridge designs, and guest speaker.

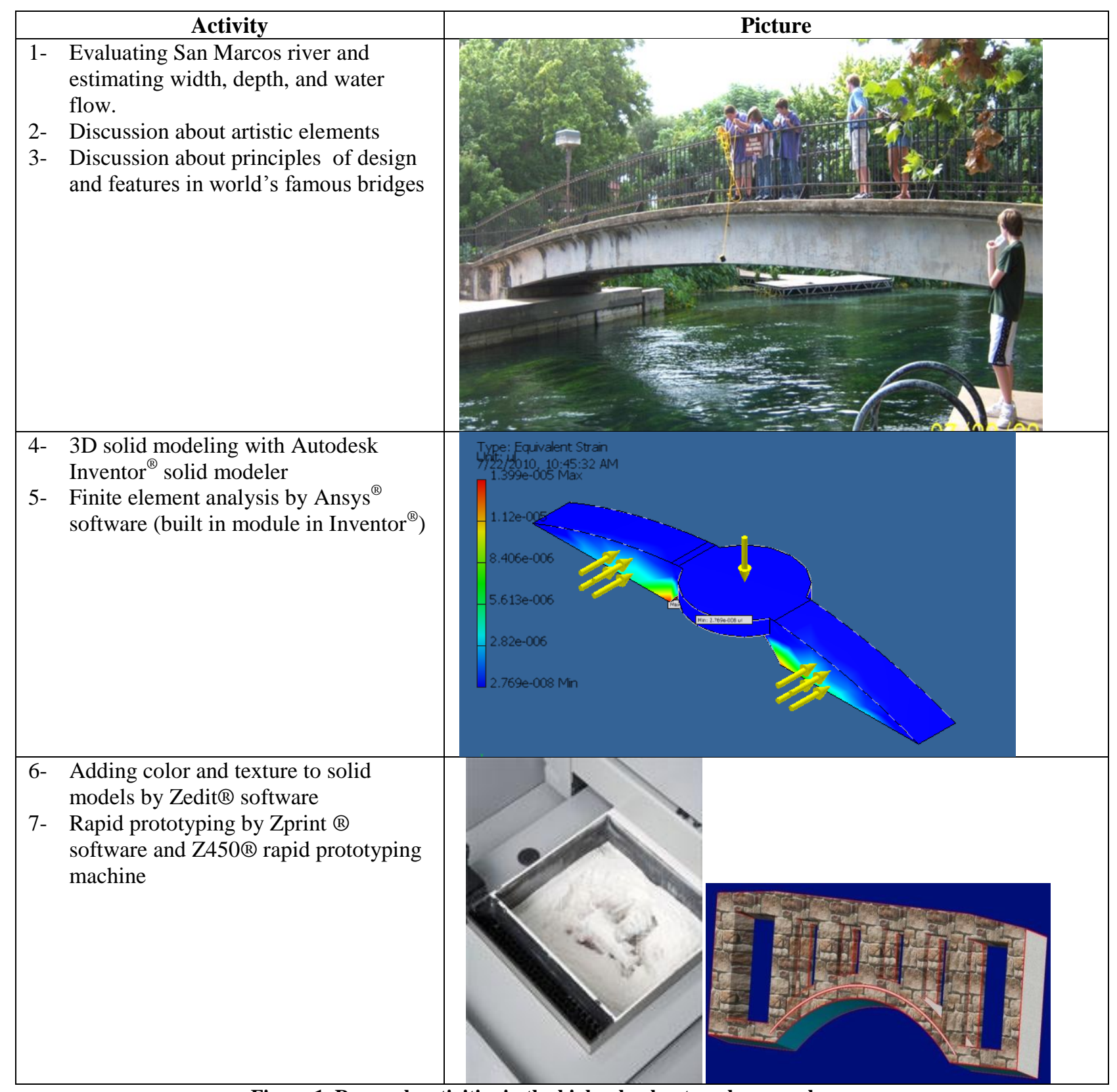

Figure 1. Research activities in the high school outreach research camp 


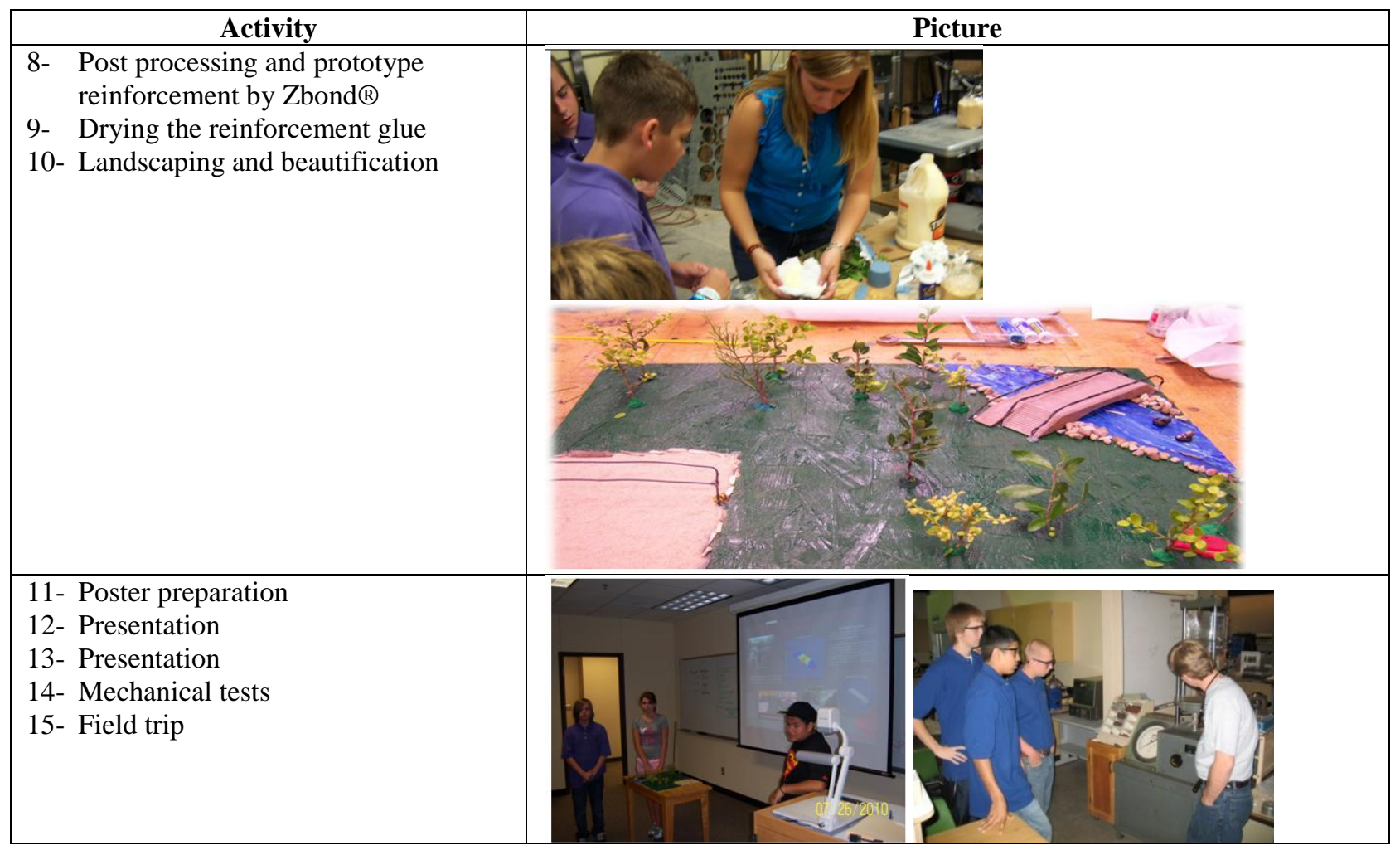

Figure 1. Research activities in the high school outreach research camp (Cont.)

\section{EVALUATION METHOD}

Pre- and post-program surveys were conducted for all participants. In pre-program survey, students provided basic demographic information and were asked about their understanding about engineering and art functions, their interest in higher education in engineering and science programs, and their skills levels in each topic to be covered during the research camp (Appendix A). Post program survey included similar questions as preprogram survey plus some additional questions regarding their degree of satisfaction of this research camp (Appendix B). Paired t-test statistical tool was used to compare the quantitative sections of the pre/post surveys (Appendix C).

In addition, an outside observer came into observe a portion of one day of research and planning. Observation included: Classroom and student interaction dynamics, student teamwork, informal discussions with students and faculty about their experiences during the course of the camp. The purpose of this observation was twofold: to gauge the level of student engagement and identify elements of the program appear to raise student's interests and alter perceptions of both engineering and art.

\section{RESULTS}

At the end of the program, students demonstrated their bridges, landscapes, and posters and also presented their approach and results. All bridges were designed in real world sizes and specification and the minimum safety factor for the bridges for the most extreme conditions (windy day, highest level of water flow, and 200 people on the bridge) was 15 . All bridges then were prototyped in the smaller scale. Artistic features and aspects were explained by student participants in end-of-camp presentations.

Student designs included inherent color and natural texture of the building materials to blend with the surroundings. In one pedestrian bridge, applied color to the underside resulted in a visual contrast to the stone that 
invites viewers to explore the underside as one would do on the river in a canoe or inner tube. Students also found creative ways to use space, such as a bridge design that provided a pedestrian overpass on two levels, one at street level and another at the river bank level. Other designs engaged the viewer by integrating a central platform space on which pedestrians can stop to reflect on the surroundings. As an engineered structure intended to promote pedestrian transportation, one bridge incorporated repetition with curvilinear shaped railings to enhance the overall form and visual movement thereby reinforcing its engineered purpose.

Because of the high quality of the projects and presentations, panel of experts unanimously decided to select all four teams as winners of this year research camp.

Qualitative results from paired t-test statistical tool illustrated that in the areas of technical tools and methods (CAD, FEA, RP, mechanical properties, principles of design, and tests), students' knowledge and skills increased significantly. Also, the knowledge of the students about engineering, manufacturing engineering, and art and design tasks and functions as a career, increased significantly. Also, for the questions regarding their interest to continue their higher education and continue their higher education in the field of manufacturing engineering the results shows significant increase in their interests. For the questions regarding their interest to continue their higher education in the STEM (science, engineering, technology, and mathematics) fields and also continue their higher education at Texas State University, the results show increase in their interests but not statistically significant. Additionally, there were some courses only in the post program survey. For the questions if the take any engineering and fine art courses (if available) in their high school and if they recommend this camp to their friends, average ratings were $9,8.3$, and 8.7 (out of 10) respectively. Also, on a scale of 1-10 (1=didn't like it, 10= loved it), the ratings averages for the camp components including, Engineering Lectures, Art Lectures, CAD Design, Tours (river, engineering, art, and material testing labs), Team Lab Work, and Poster Preparation and Presentation, were all between 7 and 9 (Appendix C).The answers for the qualitative questions including the connection between art and engineering, what they learned about the engineering process, the process of creativity and making art, and the team working and team management, compared to pre program survey, were generally satisfactory and rational (Appendix D and E).

Camp observation suggested a few key features that increase student engagement:

1. Students, in general, expressed positive attitudes toward being given a project goal and then working in independent teams to achieve that goal.

2. Students were most engaged when working in the lab on the project and expressed positive attitudes toward learning and mastering the software associated in the project development.

3. When asked about the decision to attend the camp, $100 \%$ (3) of the female students indicated they were interested in the artistic component of the camp, while two thirds (4) of the male students were interested in learning the computer programs.

\section{CONCLUSIONS AND DISCUSSIONS}

Based on the surveys and the quality of the projects assessed by the panel of experts and the program instructors, this program successfully introduced key engineering and art principles to students. The program content and duration was sufficient to familiarize a group of students with engineering tools and methods in a hands-on approach and the work was exposed to many more students through the teacher and the participants' network of friends. By factoring in artistic design considerations, student teams appeared to generate more creative solutions for pedestrian bridges.

One weakness that will be addressed later was the low number of student participants in this pilot of the program. The original intent was to target up to 20 students representing demographics of populations traditionally under-represented in engineering programs. The demographic distribution of the students includes $50 \%$ female and 25\% Hispanic. Future efforts to recruit these populations will be addressed through earlier and more target outreach described below. 
In all pre-post survey questions results show the increase of understanding and interest about the engineering education and career. One explanation why the students' interest in pursuing higher education in science and engineering "increased although the increase was not statistically significant" is that this group was not some random selected students from the entire school population. In contrast, they were all volunteers with overall strong grade point averages. Such students usually have good plan about their higher education and career from their early years of high school. However, even with this select population of students, it was clear from survey responses that student perceptions about engineering were changes. A typical response to this question is as follows: "I learned that the engineering process takes time $\&$ is best accomplished through trial \& error. Engineering allows our society to advance technologically and socially."

One of the areas that instructors were concerned before the camp was the grade and age difference between the students: from $6^{\text {th }}$ grade to senior year in high school. It turns out that, given the number of students, the broad grade range was not any major issue among them. More senior students were assigned as team leader and they were handled the job assignment and in-team training of the junior students were well.

The Ingram School of Engineering is currently expanding its outreach to additional local high school districts in central Texas under different programs such as Project Lead The Way, collaboration with E3 Alliance, $2+2$ degree program agreement with community colleges around the state, and sponsorship of Capital BEST robotics teams at the junior high and high school levels and First Lego League teams at lower levels.

\section{ACKNOWLEDGEMENT}

This material is based upon work supported by the Texas Higher Education Coordinating Board (THECB) Engineering Summer Program (ESP) and the support of the Ingram School of Engineering at Texas State University-San Marcos by providing access to its facilities and supplying equipment and supplies. Any opinions, findings, and conclusions or recommendations expressed in this material are those of the authors and do not necessarily reflect the views of THECB and Texas State University.

\section{AUTHOR INFORMATION}

Dr. Bahram Asiabanpour is an Associate Professor of Manufacturing Engineering and a Certified Manufacturing Engineer (CMfgE). He has served at Texas State University-San Marcos since 2003. He has two years work experience in a car design company in tool design and CAD/CAM positions. He has published several journal and conference papers and two book chapters in the areas of CAD data extraction, machine path generation, rapid tooling, selective inhibition of sintering (SIS) rapid prototyping process, CAD/CAM, product and process development, process optimization, and education. He has designed and taught four new senior-level courses including capstone senior design, tool design, manufacturing systems design, and computer aided design and manufacturing as well as other undergraduate and graduate courses. He has also enlisted the support of local industries and government agencies in his teaching and research activities. He is the director of the Rapid Product and Process Development (RPD) research center at Texas State University- San Marcos. He was the CoPI for an NSF REU center grant. For this grant in summer 2008 and 2009 his department hosted 20 undergraduate students to conduct research entitled "Micro/Nano Assembly Workcell Via Micro Visual Sensing and Haptic Feedback". Additionally, Dr. Asiabanpour collaborated with E3 Alliance and University of Texas at Austin as CoPI for an NSF project entitled "Central Texas Engineering Education Collaborative" to improve the supply chain for engineers. Dr. Asiabanpour is member of the Society of Manufacturing Engineers (SME) and the Institute of Industrial Engineers (IIE).

Nicole DesChamps-Benke is a metalsmith and art instructor, who lives in Helotes, Texas. She earned a Masters in Fine Arts from the University of Michigan and Bachelors of Fine Arts from The Center For Creative Studies College in Detroit, Michigan. She has taught at several institutions, including the University of Michigan, Bowling Green State University, and Adrian College. Currently, she teaches at Texas State University and at the Southwest School of Art and Craft. Over the years, her work has been selected in national juried exhibitions, shown in galleries, and featured in hardcover and periodical publications. 
Thomas Wilson is originally from Bastrop, Texas. He is a Manufacturing Engineering student at Texas State University-San Marcos. He is a research assistant at the Rapid Product and Process Development (RPD) research center in the Ingram School of Engineering. He is also serving in the United States Navy Reserves.

Matthew Loerwald is from Argyle, Texas. He began his education at Texas State University- San Marcos in the fall of 2007. He is majoring in Manufacturing Engineering with minors in Math and Physics. Matthew works as the research assistant at the Rapid Product and Process Development (RPD) research center in the Ingram School of Engineering. Outside of school, his hobbies are electronics and sports. He is expected to graduate in the spring of 2011.

Dr. Hannah Gourgey has worked for over a decade in workforce development and education in Austin. At E3 Alliance, Dr. Gourgey facilitates regional efforts to increase college and career readiness among high school graduates and cultivates partnerships with schools, community and business organizations to help drive systems change in education throughout Central Texas. Prior to joining E3 Alliance, Dr. Gourgey worked at Skillpoint Alliance, first as Managing Director of the Community Technology Training Centers and then as Deputy Director and acting Executive Director for the organization. During her tenure at Skillpoint, Dr. Gourgey spearheaded the effort that launched the High School Graduate Data Center - a regional longitudinal research project dedicated to tracking Central Texas high school graduates after they leave high school. In addition to her work in the community, Dr. Gourgey has taught at the University of Louisville and the University of North Carolina Chapel Hill and The University of Texas at Austin. Dr. Gourgey holds degrees from Northwestern University, the University of North Carolina Chapel Hill, and the University of Texas at Austin.

\section{REFERENCES}

1. Moving forward to improve engineering education, National Science Foundation publication, 2007.

2. The Perryman Group, Report: "The Potential Impact of an Initiative to Increase the Pool of Engineering and Computer Science Graduates on Business Activity in Texas", February 2007.

3. Texas Higher Education Coordinating Board. Texas higher education plan: Closing the gaps by 2015. 2002 [cited 2004 May 25]; Available from: www.thecb.state.tx.us.

4. $\quad$ Nobel prize winner autobiography: Roger W. Sperry, The Nobel Prize in Physiology or Medicine 1981 http://nobelprize.org/nobel_prizes/medicine/laureates/1981/sperry-autobio.html

5. Right Brain and Left Brain Inventory, http://painting.about.com/library/blpaint/blrightbraintable.htm

6. Taboh, J., "Can Right-Brain Thinking Change the World?", Voice of America news, http://www.voanews.com/english/AmericanLife/2009-03-23-voa43.cfm, March 2009.

7. Strong, B., "Creativity in Engineering", Texas State University- San Marcos, Ingram School of Engineering seminar, 2009.

8. Daniel Pink, "A Whole New Mind: Why Right-Brainers Will Rule the Future", Riverhead Trade, 2006.

9. $\quad$ Edwards, B., Drawing on the Right Side of the Brain, Tarcher 1989.

10. Edwards, B., New Drawing on the Right Side of the Brain Workbook: Guided Practice in the Five Basic Skills of Drawing, Tarcher 2002.

11. Edwards, D., "Artscience: Creativity in the Post Google Generation", Harvard University, 2008.

12. Zelanski, P. and Fisher, M.P. Shaping Space: The Dynamics of Three-Dimensional Design. Thomas Wadsworth Publishing. ISBN 053461394. 2007. 
APPENDIX A: Pre-research camp survey

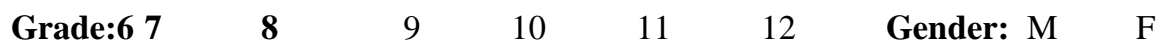

Last 4 digit of SSN\#:

1- How familiar are you with engineering tasks and functions as a career?
None $=1$
23
45
$\begin{array}{lll}6 & 7 & 8\end{array}$
9
$10=$ Fully aware

2- How familiar are you with manufacturing engineering tasks and functions as a career?

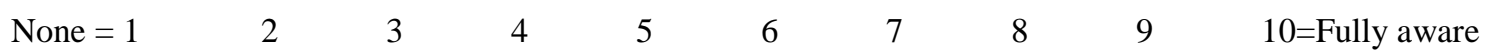

3- How familiar are you with art and design tasks and functions as a career?
None $=1$

2
34
56
$\begin{array}{lll}7 & 8 & 9\end{array}$
$10=$ Fully aware

4- In your judgment, how are engineering and art functions and tasks related?

Not related $=\begin{array}{llllllllll}1 & 2 & 3 & 4 & 5 & 6 & 7 & 8 & 9 & 10=\text { very related }\end{array}$

5- How familiar are you with principles and elements of design?
Never heard $=12$
3
45
$\begin{array}{lll}6 & 7 & 8\end{array}$
9
$10=I$ 'm Expert

6- How familiar are you with Computer Aided Design and 3 dimensional solid modeling?
Never heard $=12$
3
4
5
6
7
89
$10=$ I'm Expert

7- How familiar are you with Finite Element Method software and its applications?
Never heard $=12$
3
45
6
7
8
9
$10=I$ 'm Expert

8- How familiar are you with Rapid Prototyping technologies and their applications?
Never heard $=12$
3
4
56
7
8
9
$10=$ I'm Expert

9- How familiar are you with standards and tools for measuring mechanical properties of a part?
Never heard $=12$
3

4
56
7
89
$10=I$ 'm Expert

10- How likely it is that you continue your higher education?

Impossible $=\begin{array}{llllllllll}1 & 2 & 3 & 4 & 5 & 6 & 7 & 8 & 9 & 10=\text { Definitely }\end{array}$

11- How likely it is that you continue your higher education at Texas State?
Impossible $=1 \quad 2$
3
$4 \quad 5 \quad 6$
7
89
$10=$ Definitely

12- How likely it is that you continue your higher education in the field of science (Mathematics, Chemistry, Physics, Biology) or engineering?
Impossible $=1 \quad 2$

3

4
56
7
89
$10=$ Definitely

13- How likely it is that you continue your higher education in the field of manufacturing engineering?
Impossible $=1 \quad 2$
3
45
6
$7 \quad 8$
9
$10=$ Definitely

14- Describe your understanding about the functions and tasks of the manufacturing engineers and engineers in general? 
APPENDIX B: Post-research camp survey

All questions listed in pre-research camp survey (Appendix A) plus the following additional questions:

1- When you go to high school, will you take engineering courses (if available)?
Impossible $=1$
2
3
$4 \quad 5$
6
$7 \quad 8$
8
10=Definitely

2- When you go to high school, will you take fine arts courses (if available)?
Impossible $=$
2
3
4
56
$\begin{array}{lll}7 & 8 & 9\end{array}$
$10=$ Definitely

3- Would you recommend this camp to other friends?
Impossible = 1

23
4
56
7
$8 \quad 9$
$10=$ Definitely

4- Would you attend a similar camp again? If yes, what subjects would you like to learn about? Impossible $=\begin{array}{llllllllll}1 & 2 & 3 & 4 & 5 & 6 & 7 & 8 & 9 & 10=\text { Definitely }\end{array}$

5- On a scale of 1-10 (1=didn't like it, $10=$ loved it $)$, please rate the following camp components.
a. Engineering Lectures
Bad $=123$
$\mathrm{Bad}=1 \quad 2 \quad 3$

4
Bad $=12$
c. Cad Design
$\mathrm{Bad}=12$

3

4

$5 \quad 6$
7
89
10 Love it

d. Tours (river, engineering, art, and material testing labs)

$\begin{array}{llllllllll}\mathrm{Bad}=1 & 2 & 3 & 4 & 5 & 6 & 7 & 8 & 9 & 10 \text { Love it }\end{array}$

e. Team Lab Work

$\begin{array}{llllllllll}\mathrm{Bad}=1 & 2 & 3 & 4 & 5 & 6 & 7 & 8 & 9 & 10 \text { Love it }\end{array}$

f. Poster Preparation and Presentation

$\begin{array}{llllllllll}\mathrm{Bad}=1 & 2 & 3 & 4 & 5 & 6 & 7 & 8 & 9 & 10 \text { Love it }\end{array}$

$\begin{array}{lccccccccc}\text { g. Other } & \text { (Please Explain) } & & & & \\ =1 & 2 & 3 & 4 & 5 & 6 & 7 & 8 & 9 & 10 \text { Love it }\end{array}$

6- Describe what you think the connection between art and engineering is?

7- Tell us what you think you learned about the engineering process?

8- Tell us what you think you learned about the process of creativity and making art?

9- Tell us what you think you learned about the team working and team management?

10- Final words for the students that don't know anything about this program and want to decide if it is for them: 


\section{APPENDIX C: Pre/Post-research camp surveys data analysis by paired t-test}

Data was processed based on 11 valid answers for average for each grade (e.g., nine graders, ten graders, etc.) as identifying individual students were not possible but it was possible to find out in what grade they are in.

1- How familiar are you with engineering tasks and functions as a career?

\begin{tabular}{|c|c|c|c|}
\cline { 2 - 4 } \multicolumn{1}{c|}{} & Pre & Post & Difference \\
\hline Average & 4.36 & 7.81 & 3.45 \\
\hline Standard Deviation & & & 2.16 \\
\hline $\mathrm{t}$ & & & 1.833 \\
\hline Lower Bound & & & 2.25 \\
\hline Upper Bound & & & 4.65 \\
\hline
\end{tabular}

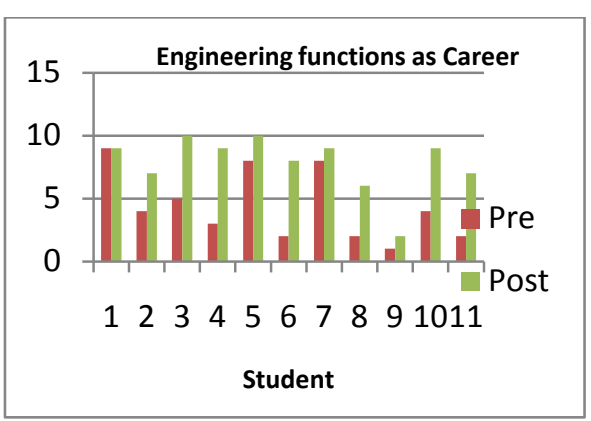

2- How familiar are you with manufacturing engineering tasks and functions as a career?

\begin{tabular}{|c|c|c|c|}
\hline & Pre & Post & Difference \\
\hline Average & 3.54 & 6.63 & 3.09 \\
\hline $\begin{array}{c}\text { Standard } \\
\text { Deviation }\end{array}$ & & & 2.41 \\
\hline $\mathrm{t}$ & & & 1.833 \\
\hline Lower Bound & & & 1.75 \\
\hline Upper Bound & & & 4.42 \\
\hline
\end{tabular}

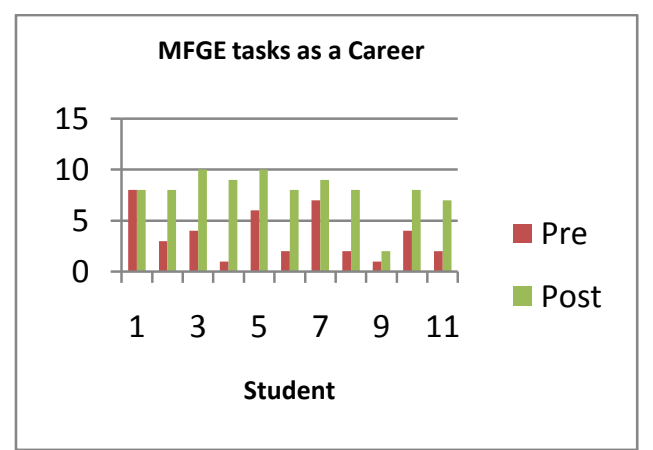

3- How familiar are you with art and design tasks and functions as a career?

\begin{tabular}{|c|c|c|c|}
\hline & Pre & Post & Difference \\
\hline Average & 4.55 & 7.64 & 3.09 \\
\hline Standard Deviation & & & 1.70 \\
\hline $\mathrm{t}$ & & & 1.83 \\
\hline Lower Bound & & & 2.15 \\
\hline Upper Bound & & & 4.03 \\
\hline
\end{tabular}

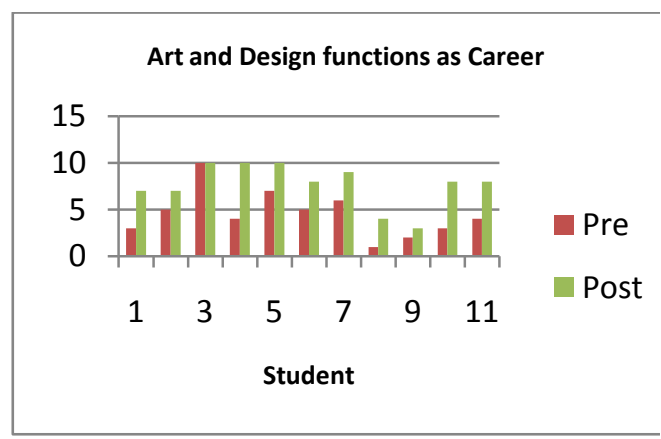


4- In your judgment, how are engineering and art functions and tasks related?

\begin{tabular}{|c|c|c|c|}
\hline & Pre & Post & Difference \\
\hline Average & 7.27 & 9.09 & 1.82 \\
\hline Standard Deviation & & & 2.09 \\
\hline $\mathrm{t}$ & & & 1.83 \\
\hline Lower Bound & & & 0.66 \\
\hline Upper Bound & & & 2.97 \\
\hline
\end{tabular}

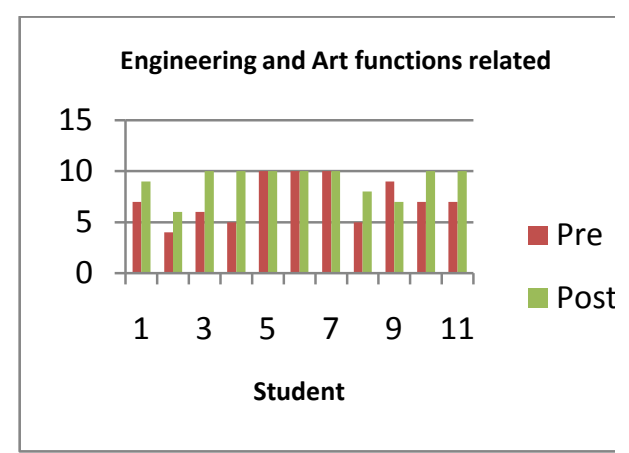

5- How familiar are you with principles and elements of design?

\begin{tabular}{|c|c|c|c|}
\hline & Pre & Post & Difference \\
\hline Average & 4.82 & 7.73 & 2.91 \\
\hline Standard Deviation & & & 2.55 \\
\hline $\mathrm{t}$ & & & 1.83 \\
\hline Lower Bound & & & 1.50 \\
\hline Upper Bound & & & 4.32 \\
\hline
\end{tabular}

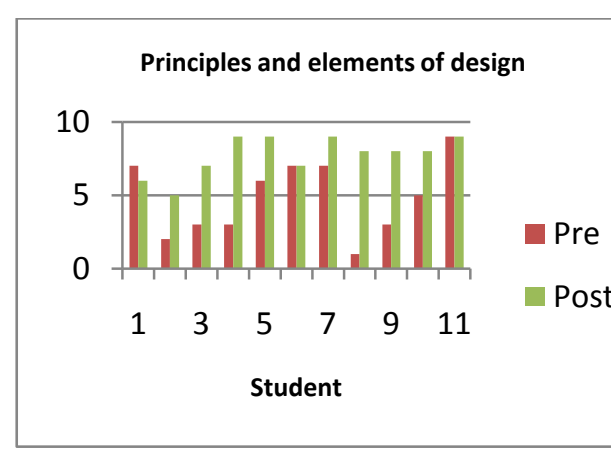

6- How familiar are you with Computer Aided Design and 3 dimensional solid modeling?

\begin{tabular}{|c|c|c|c|}
\hline & Pre & Post & Difference \\
\hline Average & 2.55 & 7.55 & 5.00 \\
\hline Standard Deviation & & & 2.32 \\
\hline $\mathrm{t}$ & & & 1.83 \\
\hline Lower Bound & & & 3.72 \\
\hline Upper Bound & & & 6.28 \\
\hline
\end{tabular}

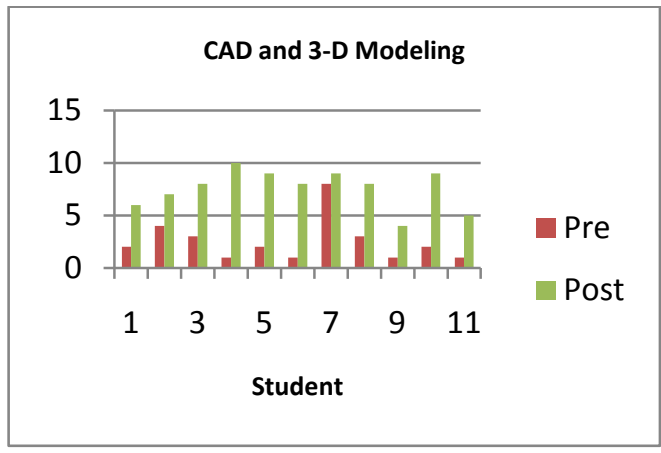

7- How familiar are you with Finite Element Method software and its applications?

\begin{tabular}{|c|c|c|c|}
\hline & Pre & Post & Difference \\
\hline Average & 1.64 & 6.36 & 4.73 \\
\hline Standard Deviation & & & 2.69 \\
\hline $\mathrm{t}$ & & & 1.83 \\
\hline Lower Bound & & & 3.24 \\
\hline Upper Bound & & & 6.21 \\
\hline
\end{tabular}

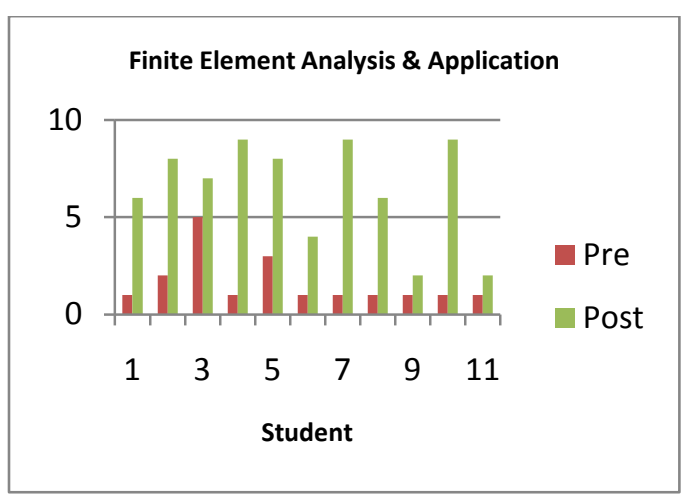


8- How familiar are you with Rapid Prototyping technologies and their applications?

\begin{tabular}{|c|c|c|c|}
\hline & Pre & Post & Difference \\
\hline Average & 1.73 & 7.27 & 5.55 \\
\hline Standard Deviation & & & 1.44 \\
\hline $\mathrm{T}$ & & & 1.83 \\
\hline Lower Bound & & & 4.75 \\
\hline Upper Bound & & & 6.34 \\
\hline
\end{tabular}

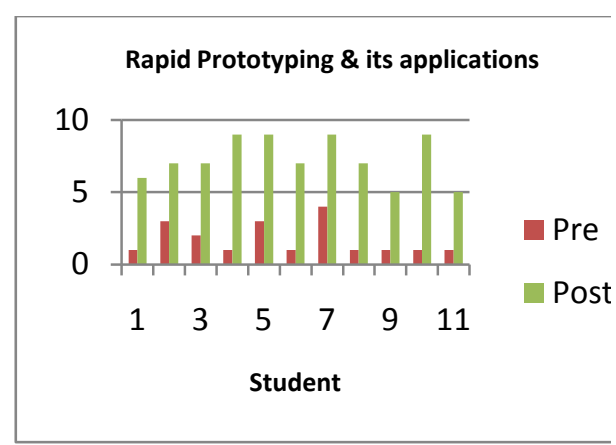

9- How familiar are you with standards and tools for measuring mechanical properties of a part?

\begin{tabular}{|c|c|c|c|}
\hline & Pre & Post & Difference \\
\hline Average & 4.00 & 7.18 & 3.18 \\
\hline Standard Deviation & & & 2.04 \\
\hline $\mathrm{t}$ & & & 1.83 \\
\hline Lower Bound & & & 2.05 \\
\hline Upper Bound & & & 4.31 \\
\hline
\end{tabular}

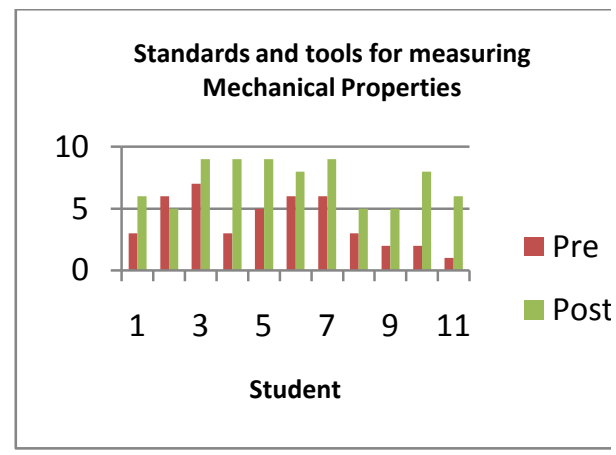

10- How likely is it that you continue your higher education?

\begin{tabular}{|c|c|c|c|}
\hline & Pre & Post & Difference \\
\hline Average & 9.30 & 9.80 & 1.58 \\
\hline Standard Deviation & & & 1.58 \\
\hline $\mathrm{t}$ & & & 1.83 \\
\hline Lower Bound & & & 0.66 \\
\hline Upper Bound & & & 2.50 \\
\hline
\end{tabular}

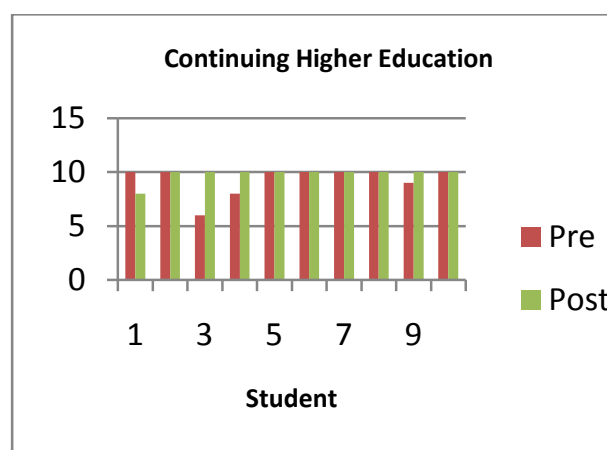

11- How likely is it that you continue your higher education at Texas State?

\begin{tabular}{|c|c|c|c|}
\hline & Pre & Post & Difference \\
\hline Average & 6.90 & 7.80 & 0.90 \\
\hline Standard Deviation & & & 1.60 \\
\hline $\mathrm{t}$ & & & 1.83 \\
\hline Lower Bound & & & -0.02 \\
\hline Upper Bound & & & 1.82 \\
\hline
\end{tabular}

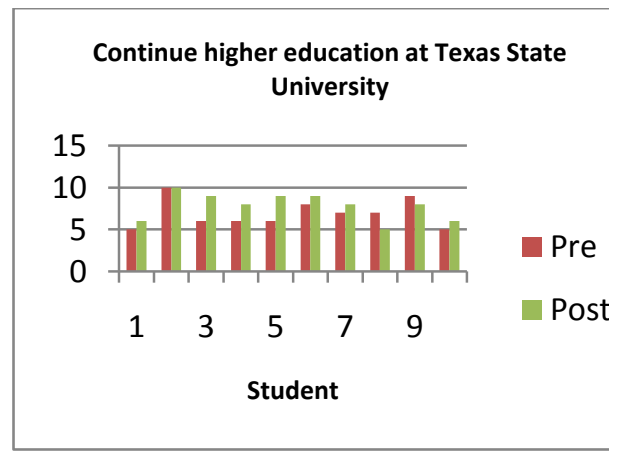


12- How likely is it that you continue your higher education in the field of science (Mathematics, Chemistry, Physics, Biology) or engineering?

\begin{tabular}{|l|l|l|l|}
\hline & Pre & Post & Difference \\
\hline Average & 8.10 & 8.80 & 0.70 \\
\hline $\begin{array}{l}\text { Standard } \\
\text { Deviation }\end{array}$ & & & 2.11 \\
\hline $\mathrm{t}$ & & & 1.83 \\
\hline Lower Bound & & & -0.47 \\
\hline Upper Bound & & & 1.87 \\
\hline
\end{tabular}

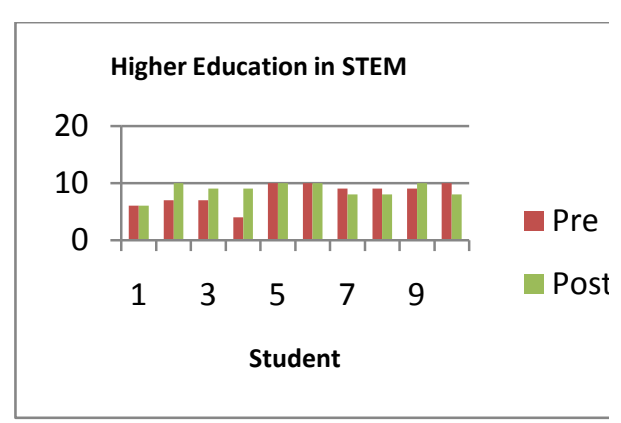

13- How likely is it that you continue your higher education in the field of manufacturing engineering?

\begin{tabular}{|c|c|c|c|}
\hline & Pre & Post & Difference \\
\hline Average & 4.90 & 6.95 & 2.05 \\
\hline Standard Deviation & & & 1.17 \\
\hline $\mathrm{t}$ & & & 1.83 \\
\hline Lower Bound & & & 1.41 \\
\hline Upper Bound & & & 2.69 \\
\hline
\end{tabular}

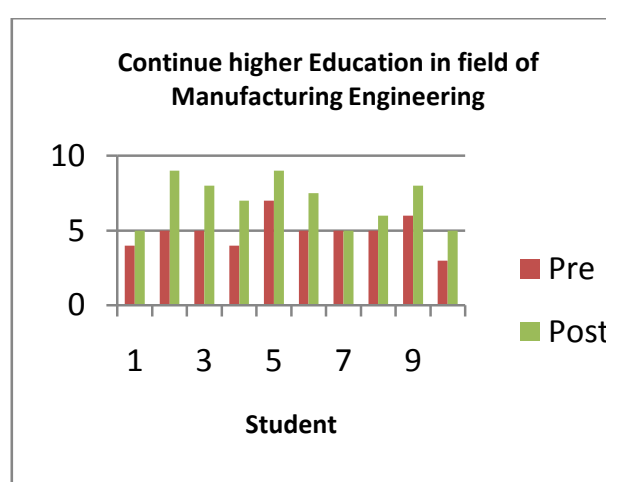

14- When you go to high school, will you take engineering courses (if available)?

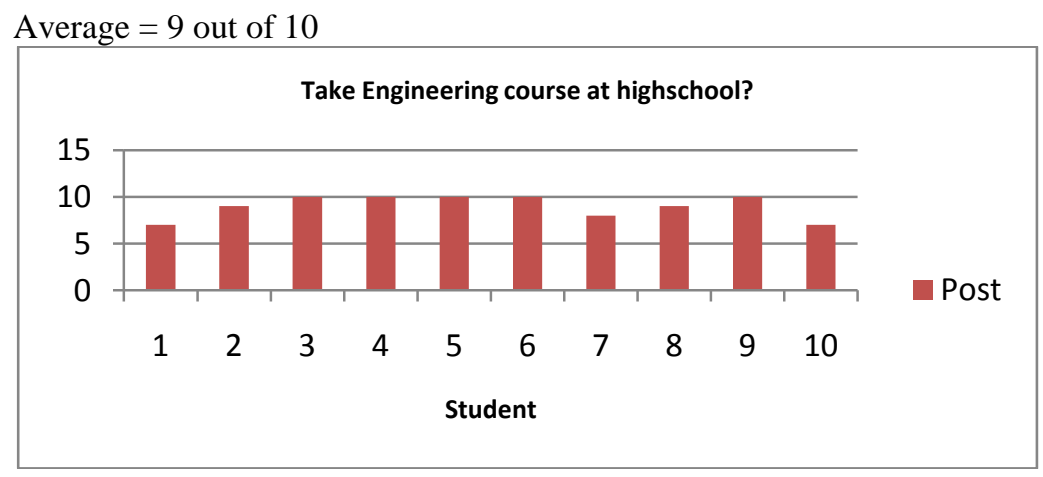


15- When you go to high school, will you take fine arts courses (if available)?

Average $=8.3$ out of 10

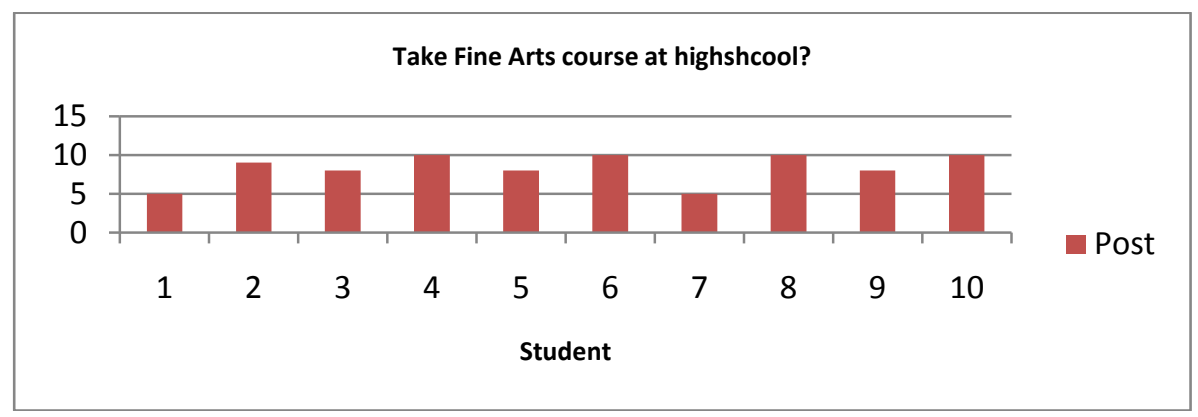

16- Would you recommend this camp to other friends?

Average $=8.7$ out of 10

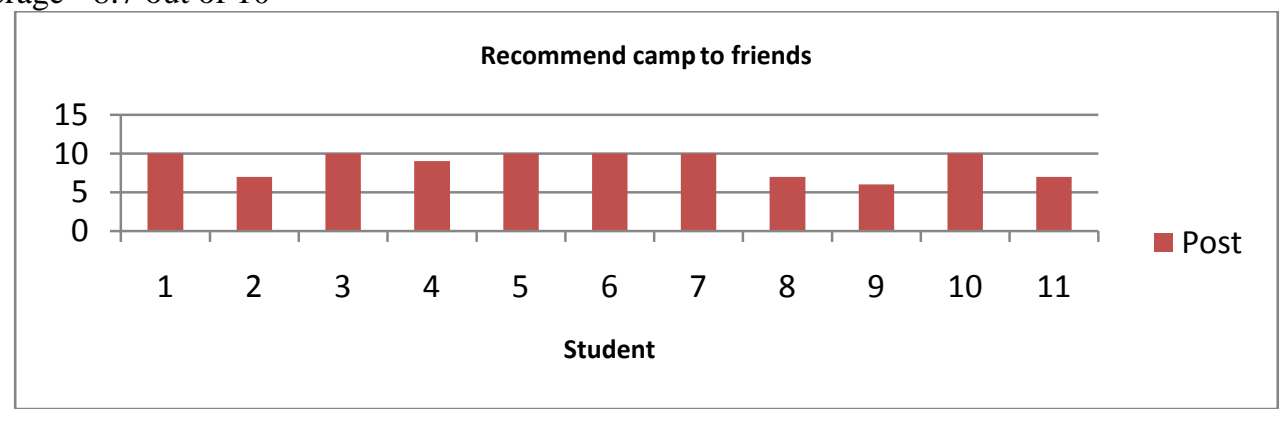

17- Describe your understanding about the functions and tasks of the manufacturing engineers and engineers in general.

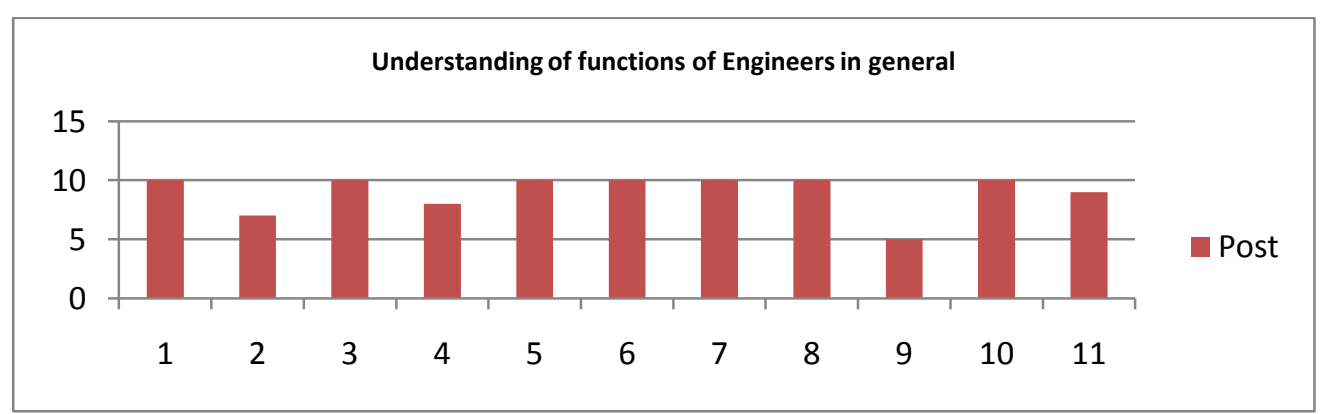


18- On a scale of 1-10 ( $1=$ didn't like it, $10=$ loved it $)$, please rate the following camp components.

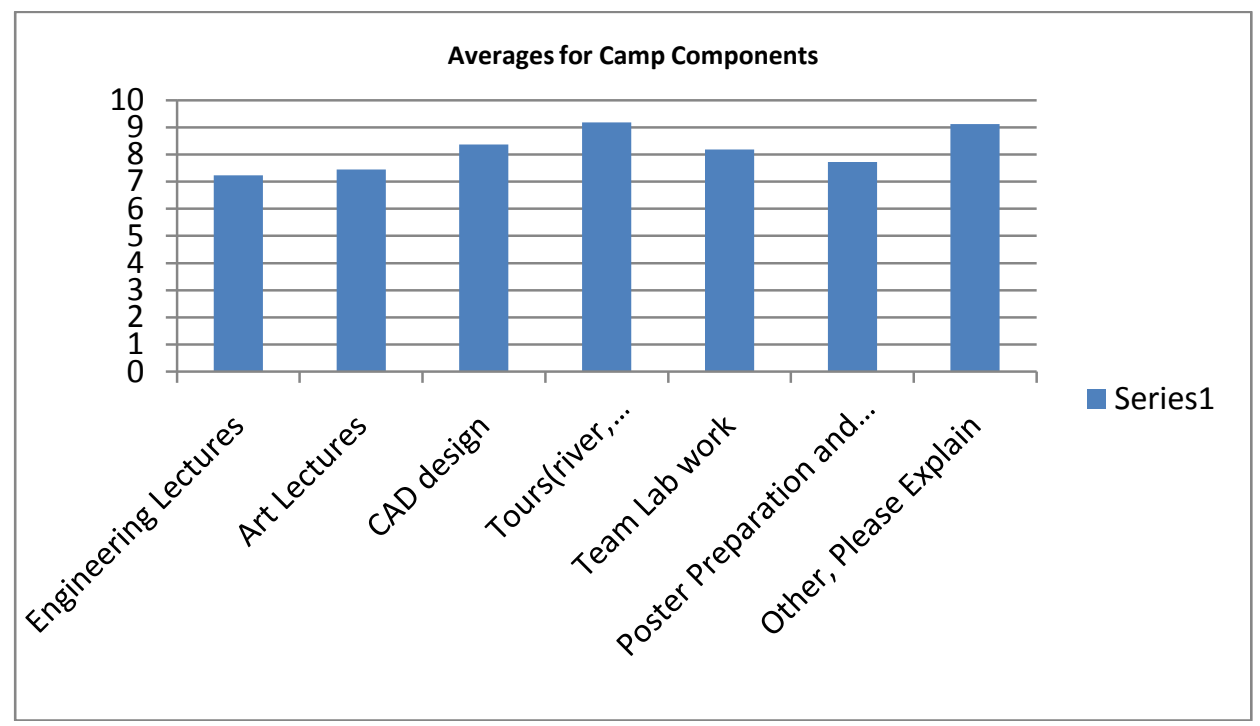

Other things they liked comments:

- Fun

- Being able to create new things

- Staff + Lunch

- Watching college students work on projects

- I wish we could have picked our own partners

- The camp

- hands on learning 


\section{APPENDIX D: Answers to qualitative question in pre-research camp surveys}

\section{Describe your understanding about the function and tasks of the manufacturing engineers and engineers in general?}

- Engineers apply many principles of physics

- Making stuff and putting stuff together. I don't know much about it, so here to find out.

- I really do not understand anything about manufacturing engineers or engineers in general but I am here to find out more about this program because it sounds interesting.

- I don't know much about it but I like putting things together.

- Building, Blueprints, software, prototyping.

- I understand that engineering in general is based upon science and mathematics.

- They are creative builders who without nothing creative would be designed.

- I understand that manufacturing engineers use math and science generally.

- Manufacturing Engineers come up with ways to facilitate production. I'm assuming they develop prototypes of products using different materials + methods of manufacturing in order to develop the most efficient (cost or supply wise) product possible.

- Materials + methods of manufacturing in order to develop the most efficient (cost or supply wise) product possible. Engineers in general develop new ideas/methods of developing...

- My understanding of engineers in general is making sure everything works, engineers are the ones who not only design things but test and check for safety hazards as well. If someone needs something fixed or built or a new design it seems to me they would find an engineer to do it. As for manufacturing engineers, I see them as the ones who make sure people can produce goods and work on the machinery to produce goods.

- I honesty have no idea. The Middle school I went to was very small and didn't tell us anything about engineering.

- Manufacturing and engineering both have a lot to do with art.

- Engineers design and build things that make everyday life possible. 


\section{APPENDIX E: Answers to qualitative questions in post-research camp surveys}

\section{1- Describe what you think the connection between art and engineering is.}

- Engineering is the basic design using art to enhance the project in various ways

- now you want something to look or be built

- The art part is about how to find new elements and structures for bridges. Engineering is for building bridges and prototypes for your artwork.

- I think they can be connected to make something beautiful

- Very close, Engineering is an art

- They both require inspiration and creativity

- Art is what people will see(appeal and character) and engineering reinforces the design taking into account sturdiness, feasibility, and efficiency

- I feel like the connection is rather large between art and engineering. If you think of them alone they most of the time wouldn't work, but when you combine them they will really design something cool.

- you have to use art skills to design your product, and engineering skills to make sure your product works.

- you can't build anything without art

- $\quad$ art is needed in the design element of engineering

2- Tell us what you think you learned about the engineering process.

- Engineering is a process, this process uses the scientific method throughout design.

- it's easy at times but hard too

- I learned more ways to make a bridge or whatever comes to mind.

- I think I learned that it's pretty easy but hard at the same time

- The whole thing(blueprints to prototype to manufacture)

- That you must first draw it out and then keep adding on

- I learned that the engineering process takes time \& is best accomplished through trial \& error. Engineering allows our society to advance technologically and socially.

- I learned engineering is a lot more about the design rather than building and testing. You can do testing before the object is built.

- Make a design, test it, decorate it, build it.

- I learned about the process of bridge building

- Engineering is very hands on and is about learning from mistakes

3- Tell us what you think you learned about the process of creativity and making art?

- There are many elements and principles of art to consider

- I think it was easy

- I think I can learn a lot more than I know now.

- I think my creativity got better

- Same as the engineering process

- It starts as an idea and then becomes reality

- Like the engineering process, art takes trial \& error. Art incorporates not only the engineering but the surrounding environment. Art + Engineering are essential components to any design.

- I learned you really don't have to have a specialty with drawing to be good with art, you just need an image in your mind of what you want.

- you first come up with a simple idea, then you keep perfecting that idea.

- I learned a lot and I know it's going to help me for school

- sometimes you have to go with the flow

4- Tell us what you think you learned about the team working and team management?

- Working as a team is critical to engineering and art design

- easy I had a good partner

- I learned to work with people I don't even know. And to help each other.

- I liked the team idea but if we could choose our team I would 
- $\quad$ Listen to what they say

- I think that there shouldn't be team management

- I learned to listen to people's ideas and that compromises are the best way to resolve conflicts

- It's much easier to do tasks if you have team mates to help you out. As far as team management sure it has its perks but it definitely takes more work to be in charge of everyone rather than just yourself.

- everyone needs something to do, \& they have to do it correctly, otherwise teamwork doesn't work

- I learned that if you have no team work you won't be able to build anything leading is not about being in control.

5- Final words for the students that don't know anything about this program and want to decide if it is for them.

- If the student wants to bring rigor to their ideas in engineering, then they need to consider this program in their lives

- They should come to it. It's a whole lot of fun to be at Texas State!

- It's fun

- It is awesome

- It was great and challenging

- This program is an opportunity for prospect engineers to learn the ART of engineering.

- Even if you don't want to be an engineer it's a good program to meet some friends have a good time and learn a lot in a good environment.

- Go for it.

- If you like or want to know more about engineering go to the camp.

- This program is for students who want to learn about engineering through hands on experience 
NOTES 